\title{
New Three-Way Split Mold Design and Experimental Procedure for Testing Soft, Grouted Soils
}

\begin{abstract}
Soil grouting has become a popular method for soil improvement in recent years. Grouting is generally intended to increase a soil's strength, increase its liquefaction resistance, or reduce its hydraulic conductivity. Soil grouting involves the injection, permeation, or mechanical mixing of cementitious, silica, or clay grout into a soil deposit. With the increase in popularity of these methods comes the issue of testing grouted soils to verify the expected soil improvement. While some of the methods and materials mentioned result in soils that are sufficiently cemented to produce trimmable specimens that can stand under their own weight, other methods produce softer materials that are very difficult to sample or even to recreate and test in the lab. Preparing such soft samples in the laboratory poses two challenges: 1) if the specimen is prepared in the triaxial cell directly, the grouting process might not be feasible because of the porous stones and small diameter tubing in the triaxial cell; and 2) if the specimens are prepared outside the triaxial cell, soft specimens might not be able to stand under their own weight without significant strains and damage to the soil structure. This paper will thoroughly describe a three-way split mold specifically designed to accommodate the permeation and testing of soils that are too soft or too weak to be easily sampled or tested in the lab. A simple procedure outlining the use of this three-way split mold will also be described. Finally, the results from a series of consolidated undrained, monotonically loaded triaxial tests will be presented as an example of the split mold application. These tests utilized the new three-way split mold for sample preparation of loose Ottawa sand permeated with a thixotropic bentonite suspension.
\end{abstract}

KEYWORDS: grouting, split mold, consolidated undrained triaxial, liquefaction, soil improvement

\section{Nomenclature}

$\mathrm{Cc}=$ coefficient of curvature

$\mathrm{CO}_{2}=$ carbon dioxide

$\mathrm{CS}=$ critical state

$\overline{\mathrm{CU}}=$ consolidated undrained monotonic triaxial tests with pore pressure measurements

$\mathrm{Cu}=$ coefficient of uniformity

$D_{10}=$ diameter with $10 \%$ of the soil finer

$D_{50}=$ diameter with $50 \%$ of the soil finer (average diameter)

$D_{60}=$ diameter with $60 \%$ of the soil finer

$e_{\max }=$ maximum void ratio

$e_{\min }=$ minimum void ratio

Gs $=$ specific gravity of solids

$\mathrm{LL}=$ liquid limit

NCEER $=$ National Center for Earthquake Engineering Research

$\mathrm{PL}=$ plastic limit

$\mathrm{PVC}=$ polyvinyl chloride

$R=$ stress ratio

$R_{\mathrm{CS}}=$ stress ratio at $\mathrm{CS}$

$R_{\mathrm{UIS}}=$ stress ratio at UIS

Manuscript received November 30, 2010; accepted for publication May 20, 2011; published online July 2011.

${ }^{1}$ Assistant Professor, Dept. of Civil, Architectural \& Environmental Engineering, Univ. of Texas at Austin, Austin, TX 78712. (Corresponding author), e-mail: ElMohtar@mail.utexas.edu

${ }^{2}$ Geotechnical Engineer, Golder Associates, Lakewood, CO 80228, e-mail: dennis_rugg@golder.com

$$
\begin{aligned}
\text { SPP } & =\text { sodium pyrophosphate } \\
\text { UIS } & =\text { undrained instability state } \\
\text { USCS } & =\text { Unified Soil Classification System } \\
\left(\varepsilon_{a} \%\right) & =\text { axial strain } \\
\phi^{\prime} & =\text { effective internal friction angle } \\
\phi^{\prime} \mathrm{CS} & =\text { effective internal friction angle at CS } \\
\phi^{\prime} \mathrm{UIS} & =\text { effective internal friction angle at UIS } \\
q & =\text { deviatoric vertical stress }\left(\sigma_{1-} \sigma_{3}\right) \\
p^{\prime} & =\text { mean effective stress }[1 / 2]\left(\sigma^{\prime}{ }_{1}+\sigma^{\prime}{ }_{3}\right)
\end{aligned}
$$

\section{Introduction}

Liquefaction of loose, saturated sands poses a major threat to infrastructure worldwide due to the large deformations observed when this phenomenon occurs. Many soil improvement methods have been introduced to counteract this threat, the easiest of which is soil compaction by different methods. However, soil compaction (especially dynamic compaction) can often be harmful to existing structures on or nearby liquefiable soil deposits. Thus, permeation grouting or "passive site remediation" has been proposed for stabilizing liquefiable soil deposits at sensitive or developed sites. Passive site remediation techniques, as described by Gallagher (2000), involve the penetration of various flowable grouts into the pore spaces of a liquefiable soil deposit, under low pressures, such that the initial soil fabric is not significantly disturbed.

Researchers have proposed the use of many different grouting materials, including cement based grouts (e.g., Dano et al. 2004; Dupla et al. 2004), colloidal silica grouts (e.g., Maher et al. 1994; Liao et al. 2004; Gallagher et al. 2007; Gallagher and Lin 2009), 
and clay grouts (Haldavnekar et al. 2003; El Mohtar et al. 2008). Cement and colloidal silica grouts tend to produce soils that are sufficiently strong to allow for trimming and testing under unconfined conditions. Clay grouts; on the other hand, can produce softer soil specimens that may not be able to stand under their own weight. This creates an issue when trying to verify the improved soil's parameters. These soils are nearly impossible to sample and very difficult to create and test in the lab.

Verifying the properties of the improved soil is essential to describe the effectiveness of the utilized grout. In 1997, the NCEER modified and updated a simplified procedure by Seed and Idriss (1982) for assessing liquefaction resistance by correlating the standard penetration blow counts or the cone penetration resistance to a liquefaction potential. However, Gallagher (2000) states that this correlation may not be adequate for grouted soils since there is not much data to make the correlation. Thus laboratory testing must be implemented. The preparation of laboratory samples permeated with cement or colloidal silica grout is not a trivial matter; however, these soil mixtures are generally adequately cemented to allow for easy trimming and sample preparation after permeation and curing. Specimens permeated with clay suspensions can be more difficult to trim and prepare in the lab since they are softer and generally require constant confinement.

A method for permeating and testing soft, grouted, cohesionless soils will be presented in this paper. Tests were run specifically on loose, saturated sand permeated with thixotropic bentonite suspensions. The equipment and procedures described herein could be used for testing a wide variety of soft, permeated soils under many different conditions.

\section{Background}

Many of the available soil improvement methods have been discussed in depth by Welsh (1987), Van Impe (1989), Hausmann (1990), Broms (1991), Bell (1993), Mosely (1993), and Kramer (1996). These authors discuss various topics, including densification, reinforcement, drainage, and grouting. Much of the discussion on grouting methods involves the injection, permeation, or mechanical mixing of cementitious, silica, or clay grouts. The improved performance imparted by cement or silica is due to irreversible chemical bonds (Maher et al. 1994; Gallagher and Mitchell 2002). These bonds cannot be recovered once broken, but these materials result in soils that are adequately cemented and thus easily sampled, trimmed, and tested.

Dano et al. (2004) investigated the use of cement grouts for soil stabilization. The authors prepared specimens of two different sands: Fontainebleau sand and Seine River alluvial sand. The specimens were prepared in 80 or $100 \mathrm{~mm}$ diameter PVC rigid tubes that were $900 \mathrm{~mm}$ long. The sand was air pluviated into the tubes with zero drop height and then either flushed with water or kept dry. Afterwards, the sand was permeated with cement grout from bottom to top at a constant flow rate of $180 \mathrm{~mL} / \mathrm{min}$. After permeation, the columns were cured in a temperature and humidity controlled room for 28 days. Following the curing period, the cemented sand was extruded from the tube and four specimens were trimmed from each column to be tested either in unconfined compression or drained triaxial shear. Zebovitz et al. (1989), Benhamou (1994), and Schwarz and Krizek (1994) have all used similar specimen preparation methods to prepare cement grouted sands.

Dupla et al. (2004) investigated permeation and stabilization using cement-bentonite grout. The permeation columns were $80 \mathrm{~mm}$ in diameter and $1040 \mathrm{~mm}$ in height (five $200 \mathrm{~mm}$ sections). The columns were made out of plexiglass and included 5 pore pressure transducers equally spaced along the entire length. A $40 \mathrm{~mm}$ thick layer of gravel was placed at the bottom of the column to prevent sand from entering the injection port and to allow for a uniform diffusion of the grout into the sand. The sand was air pluviated into the column, flushed with $\mathrm{CO}_{2}$, and then flushed with water. The grouting was performed with a diaphragm pump with an adjustable flow rate (0-600 $\mathrm{mL} / \mathrm{min})$. The grouted columns were allowed to cure under water for 28 days. After the curing period, the column was trimmed into 5 specimens and unconfined compression tests were performed on each specimen. The common 28-day resting period for the Dupla et al. (2004) and Dano et al. (2004) studies is a result of ASTM C39/ C39M, which specifies a 28-day strength for concrete testing (and many other international standards). Both investigations produced soil specimens that were cemented, easily trimmed, and were sufficiently strong to be tested unconfined.

Gallagher and Lin (2009) permeated columns of Nevada or Ottawa sand with colloidal silica grout. The permeation setup consisted of three $300 \mathrm{~mm}$ sections made of $100 \mathrm{~mm}$ internal diameter transparent PVC aligned on top of each other. Each of the three sections was split vertically to facilitate removing the sand post grouting. The bottom section was assembled on the bottom platen and a metal filter screen was used at the bottom of the column to prevent the inlet channel from clogging. A $45 \mathrm{~mm}$ thick gravel layer was placed on top of the metallic screen and the sand was then placed through water pluviation to fill the first section. The second two sections were then assembled one at a time following the same procedure. The specimen was then flushed with tap water for 2-3 days before grouting. Following grouting, the columns were allowed an initial gel time, after which the stabilized columns were trimmed, covered in plastic wrap and aluminum foil, and stored for "at least 4 times the initial gel time." Again, these specimens were strong enough to be trimmed and tested unconfined. The authors concluded that the measured unconfined compressive strengths of the specimens (40-60 $\mathrm{kPa})$ were high enough "to be able to mitigate the liquefaction risk."

Haldavnekar et al. (2003) and El Mohtar et al. (2008) have investigated the use of thixotropic bentonite clay suspensions to reduce the liquefaction susceptibility of clean sands. The sand and bentonite were dry mixed and air pluviated into a triaxial specimen, then flushed with $\mathrm{CO}_{2}$ and water. The specimens were allowed enough time for the bentonite and water to form a gel-like structure that contributes to the cyclic strength of cohesionless soils. This approach was first used to overcome the complications of grouting sands with bentonite grouts. Conversely to the easily trimmed, cemented structure created by permeation with cementitious or silica grouts, the grouted sand created by permeation with bentonite clay grouts is soft and not cemented. This results in soil that cannot easily be sampled or trimmed for triaxial testing, and is too soft to stand on its own without continuous confinement, let alone being tested for unconfined compressive testing.

Finally, El Mohtar (2008) investigated the use of bentonite clay suspensions as a permeation grout material. This study 


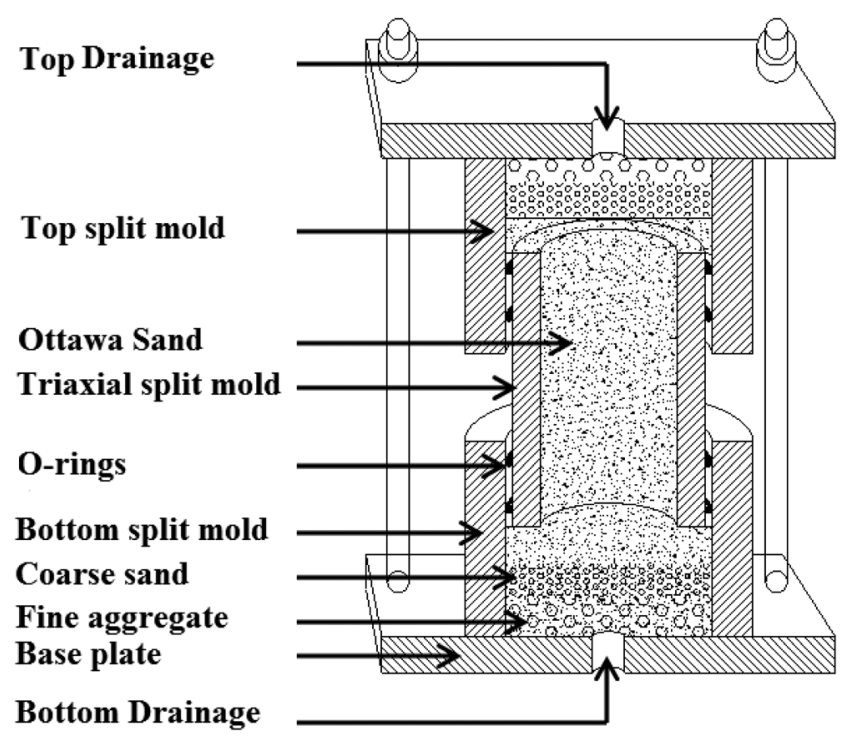

FIG. 1-Schematic of the three-way split mold.

utilized an early three-way split mold design that allowed for the permeation of a $72 \mathrm{~mm}$ diameter sand specimen. The three-way mold could then be partially disassembled for trimming into a triaxial specimen while keeping the central portion of the specimen supported by the inner split mold.

The current paper describes a modified and updated three-way split mold designed specifically for permeating specimens that require confinement during trimming and triaxial specimen preparation. The following sections will describe, in detail, the mold and its dimensions and the procedure used for permeation and trimming. The designed mold allows for the placement of filter materials at the top and bottom of the sand specimen to allow for a uniform grouting front through the whole specimen length. The mold also applies some confinement to the specimen throughout the preparation process up to placement in the triaxial setup. Finally, the results of consolidated undrained monotonic triaxial tests $(\overline{\mathrm{CU}})$ on loose, saturated Ottawa sand permeated in the new three-way split mold will be presented. These tests will indicate the repeatability and uniformity of specimens produced with this new three-way split mold and its effectiveness in maintaining continuous confinement to the grouted sand.

\section{Development of the Three-Way Split Mold}

All current literature on preparing grouted sand specimens focuses on using some form of a rigid wall column permeation setup and relies on the grouted sand having enough strength to be extruded out of the column, trimmed, and tested. However, none of the documented methods can be used to prepare non-cemented grouted specimens since all the methods require removing the specimens out of the permeation mold before testing. Therefore, there is a need to develop a new permeation mold that provides some confinement throughout grouting, storing, trimming, and sample preparation. In addition, the new mold should allow for a coarse material filter at the bottom (and top if needed) to provide a uniform grout front through the final specimen. The following sections describe the development of a new three-way split mold that was specifically designed for preparing triaxial specimens that were permeated with non-cementing grouts. This mold allows for the creation of a soil specimen that will not leave the central split mold (similar to the split mold traditionally used for preparing sand triaxial specimens) until it is securely placed on the base of the triaxial cell under a vacuum.

First, the conceptual design, sketch, and first generation mold will be presented, followed by a detailed description of the second generation mold and the final design drawings. The details of the sample preparation method will be described for loose, saturated Ottawa sand specimens that were permeated with a thixotropic bentonite suspension. This procedure could be further modified for testing soils permeated with various grouting materials.

\section{Schematic Design and First Generation Mold}

Figure 1 shows a schematic of the conceptual design that both the first and second generation molds were based upon. The threeway split mold consists of 5 main pieces: the top plate, the top split mold, the central split mold, the bottom split mold, and the base plate. The base and top plates need to be fitted with an inflow and an outflow valve, respectively, for flushing the specimens with $\mathrm{CO}_{2}$, water, and finally grout. The top, central, and bottom split molds should be split along the direction of grouting. The top and bottom split molds will be dissembled after grouting is complete in order to trim out the excess sand/filter material. Meanwhile, the central split mold will not be dissembled until the specimen is placed in the triaxial cell and is under vacuum. This sequence ensures that the grouted sand remains under a minimum amount of confinement from the end of sand placement in the mold up to the end of the triaxial test. All of the pieces should be precisely machined and fitted with the proper O-rings to create a holistic device that is air and water tight to approximately 400 $\mathrm{kPa}$.

The central split mold hosts the final triaxial specimen inside the latex membrane wrapped around the top and bottom of the mold. The top and bottom split molds allow for placing a coarse material filter and an additional layer of the same sand to be tested. This increases the uniformity of the grouted sand within the central split mold by (1) having a more horizontal grout front penetrating the sand because of the higher hydraulic conductivity of the coarser filter material; and (2) through trimming out any caking that might occur at the interface between the filter material and the tested sand.

As described previously, the first generation three-way split mold design was proposed by El Mohtar (2008) (see Fig. 2(a)). The original design utilized a typical triaxial split mold, two offthe-shelf pipe repair clamps (Fig. 2(b)), two plexiglass plates, and four threaded rods. The two plexiglass plates were fitted with inlet and outlet valves and used as the top and bottom plates. The pipe repair clamps were placed on the top and bottom one-third of the split mold; the rubber interior allows for forming a seal between the clamps and both the central split mold and the top and bottom plexiglass plates. While the pipe repair clamps did not split into two separate pieces, loosening the clamps allowed for a large enough gap between the central split mold and the pipe repair clamps to dissemble the setup for trimming. The threaded rods 


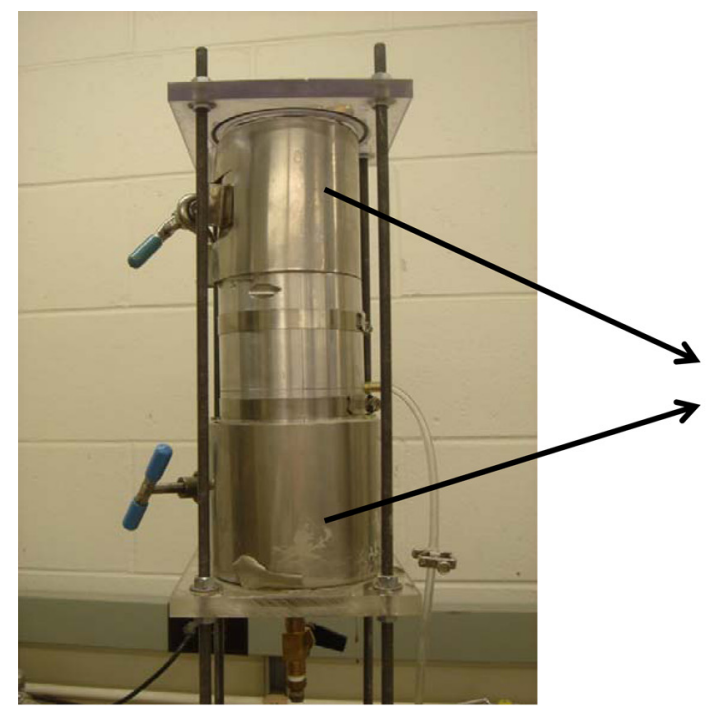

a) First generation three-way split mold

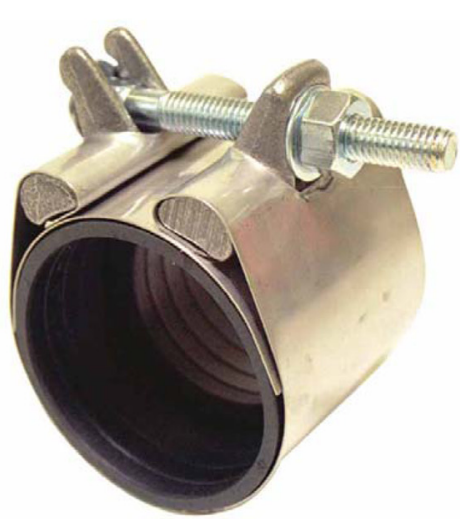

b) Pipe repair clamps

FIG. 2-First generation three-way split mold from El Mohtar (2008).

were used to hold the five pieces together. While this design proved the possibility of using the three-way split mold to prepare "undisturbed" soft grouted triaxial specimens, the design required many upgrades to facilitate the process and improve the quality of the final specimen.

\section{Second Generation Mold}

Figure 3 shows a detailed design drawing of the second generation three-way split mold (referred to as split mold for the remainder of the paper). Figure 3 shows half of the assembled mold (middle),

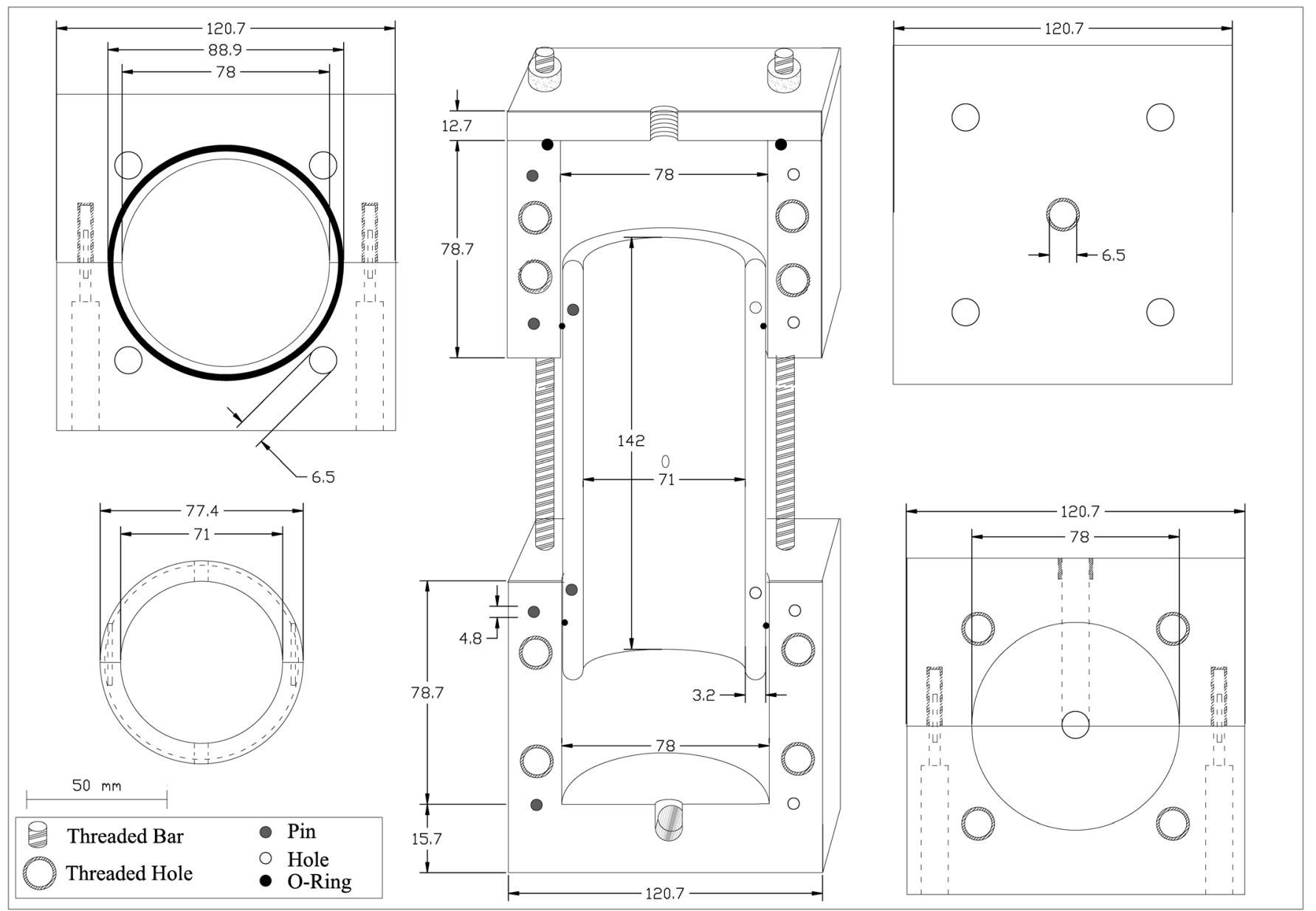

FIG. 3-Detailed design drawing of the second generation three-way split mold. 
plan view of the top cap (top right), plan view of the top split mold (top left), plan view of the central split mold (bottom left), and plan view of the bottom split mold (bottom right). The pipe repair clamps were replaced with true top and bottom split molds and the base plate was incorporated into the bottom split mold to provide a more rigid and stable system. All of the parts (except for the threaded rods and bolts which were made out of steel) were made of 6061 Aluminum since it is soft enough for precise machining while strong enough to sustain the expected pressures.

The top cap is a $120.7 \mathrm{~mm}$ square and has a thickness of 12.7 $\mathrm{mm}$. The center of the top cap is fitted with a threaded hole for the split mold's exit valve. Additionally, four $6.5 \mathrm{~mm}$ diameter unthreaded holes were drilled at the four corners for the threaded rods to pass through for the final assembly.

The top split mold was machined out of a rectangular aluminum block that has a $120.7 \mathrm{~mm}$ square base and is $78.7 \mathrm{~mm}$ thick. A $78 \mathrm{~mm}$ diameter cylinder was drilled at the center of the square face of the block throughout its whole thickness. The hollow block was then split vertically into two identical parts. Each half of this split mold was fitted with two $4.8 \mathrm{~mm}$ thick aluminum dowel pins on one side and two $4.8 \mathrm{~mm}$ diameter pinholes on the other. These pins were placed $19.5 \mathrm{~mm}$ (one/fourth the length of the top split mold) from the top and bottom of the split mold to allow for alignment of the two halves when assembled. Four 76.2 $\mathrm{mm}$ long hex-screws (6.4 $\mathrm{mm}$ diameter) were used to hold the two halves together after assembling. On one of the halves, four 6.4 $\mathrm{mm}$ threaded holes were drilled to tighten the screws into, while on the other half a $6.5 \mathrm{~mm}$ unthreaded hole was drilled throughout the width of the section for the screw to pass through. This hole was doubled in size for the first $38 \mathrm{~mm}$ to allow for the whole screw to be embedded inside the mold. The upper face of the top split mold has an O-ring groove with an outer diameter of 88.9 $\mathrm{mm}$ machined into it. The groove is $2.7 \mathrm{~mm}$ wide and $1.5 \mathrm{~mm}$ deep. The O-ring in this groove forms a seal between the top cap and the top split mold. Finally, four $6.5 \mathrm{~mm}$ diameter unthreaded holes were drilled vertically at the four corners of the split mold for the threaded rods to pass through for the final assembly.

The central split mold is similar to any standard split mold used for preparing sand triaxial specimens with two major differences to accommodate the specifics of its use:

(1) It has a much thinner wall than a typical triaxial split mold. The thinner walls lead to smaller inside diameter of the top and bottom split molds, which in turn minimizes the amount of material that needs to be trimmed later on. More important, the thinner walls cause minimal change in the seepage velocity of the grout when its front reaches the central split mold by reducing the change in cross-sectional area under the constant flow rate.

(2) The height to diameter ratio is equal to 2 . The grouted sand inside the central split mold will end up forming the triaxial specimen, and therefore, needs to have a height to diameter ratio of 2. Standard triaxial split molds usually have a lower portion that wraps around the bottom platen of the triaxial cell to provide stability and an airtight seal between the membrane and the mold. In the setup presented here, the membrane is folded around the top and bottom of the split mold to form the tight seal for applying vacuum later (see Fig. 6, to be presented later).

The central split mold is $3.2 \mathrm{~mm}$ thick with an inside diameter of $71 \mathrm{~mm}$ and a height of $142 \mathrm{~mm}$. Each of the two halves has a $1.6 \mathrm{~mm}$ aluminum dowel pin and a $1.6 \mathrm{~mm}$ hole placed at $35 \mathrm{~mm}$ from the top and bottom ends. These pins and holes ensure the proper alignment of the central split mold during assembly. Two hose clamps are used to hold the central split mold together during the final setup. In the center of each half of the central split mold is a fitting for a vacuum line. These fittings are used to apply vacuum between the membrane and the mold in order to allow for the membrane to take the same shape as the central split mold. A $1.9 \mathrm{~mm}$ wide and $1.2 \mathrm{~mm}$ deep O-ring grove was machined $25.4 \mathrm{~mm}$ from each end of the central split mold. The O-rings used in this groove help to create a leak-free seal between the central split mold and the top and bottom split molds. The $25.4 \mathrm{~mm}$ space between the end of the mold and the O-ring will have the latex membrane rolled over it until the specimen is placed in the triaxial cell.

The bottom split mold was machined out of a rectangular block of aluminum with a $120.7 \mathrm{~mm}$ square base and a $95.3 \mathrm{~mm}$ thickness. Again, a $78 \mathrm{~mm}$ diameter cylinder was hollowed out at the center of the square side of the block to a depth of $79.6 \mathrm{~mm}$. The $78 \mathrm{~mm}$ diameter was calculated to account for the outer diameter of the central split mold $(77.4 \mathrm{~mm})$ and twice the thickness of the latex membrane that will be rolled over the central split mold $(0.6$ $\mathrm{mm})$. The hollow block was then split vertically into two identical parts. Each half of this split mold was fitted with two $4.8 \mathrm{~mm}$ thick aluminum dowel pins and two $4.8 \mathrm{~mm}$ diameter pinholes. Each half of the bottom split mold was also machined with four holes for the locking screws in a similar configuration as described for the top split mold. Four $6.4 \mathrm{~mm}$ threaded holes (two in each half of the split mold) were drilled vertically at the four corners; these four holes are aligned with the unthreaded four holes at the corners of the top split mold and the top cap. Two threaded rods (6.4 $\mathrm{mm}$ diameter) are rigidly attached to each half of the bottom split mold; these rods run through the top split mold and the top cap and are used to support the top split mold as well as to tighten the top cap in place. Finally, the solid base of the bottom split mold was drilled with a $10.2 \mathrm{~mm}$ diameter drainage hole to be fitted with an inlet/flushing valve. First, a vertical hole was drilled at the center of the hollow cylinder created in the bottom split mold; then this hole was continued in the horizontal direction to the side of one of the halves.

Figure 4 shows a photograph of the partially assembled split mold, displaying all of its parts except for the top cap. The top and bottom split molds are not completely assembled to show the alignment pins, holes, and threaded holes to hold the final assembly together. Also seen in Fig. 4 is the vacuum inlet to help stick the latex membrane to the inside of the central split mold and the inflow valve used to flush the sand with $\mathrm{CO}_{2}$, water, and the grout. With the threaded rods screwed into the bottom split mold, the assembled three-way split mold can stand on its own even when partially assembled.

While the first generation mold utilized readily available materials to create a mold that adequately performed the desired function, there was a need to create a holistic device designed specifically for permeation and triaxial specimen preparation. For 


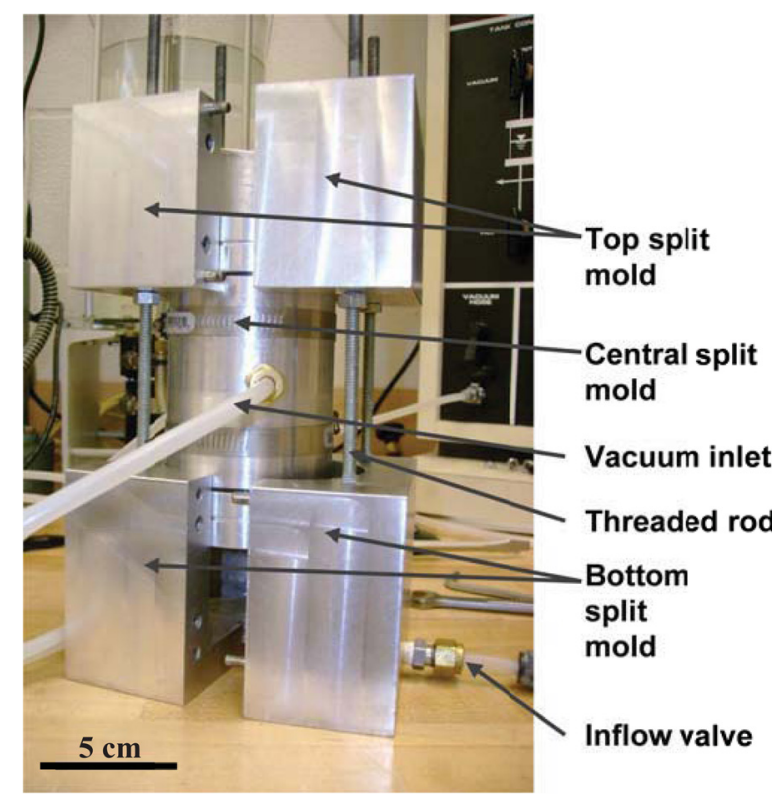

FIG. 4-Partially assembled three-way split mold (except for top cap).

the first generation mold, the maximum grouting pressure was limited because of various leaks that occurred when the pressures exceeded $75 \mathrm{kPa}$. This was mainly due to difficulties in consistently assembling the setup since the different components were not originally designed to be used together. The second generation mold was very precisely machined, sturdier than the first generation mold, and easier to work with due to its square, stable design. The square cross section of the top and bottom split molds, along with the alignment provided by the four threaded rods, allow for easier trimming of the top and bottom of the specimen and, therefore, reducing the disturbance to the final grouted specimen inside the central split mold. Additionally, the second generation mold allows for using higher grouting pressures in excess of $450 \mathrm{kPa}$.

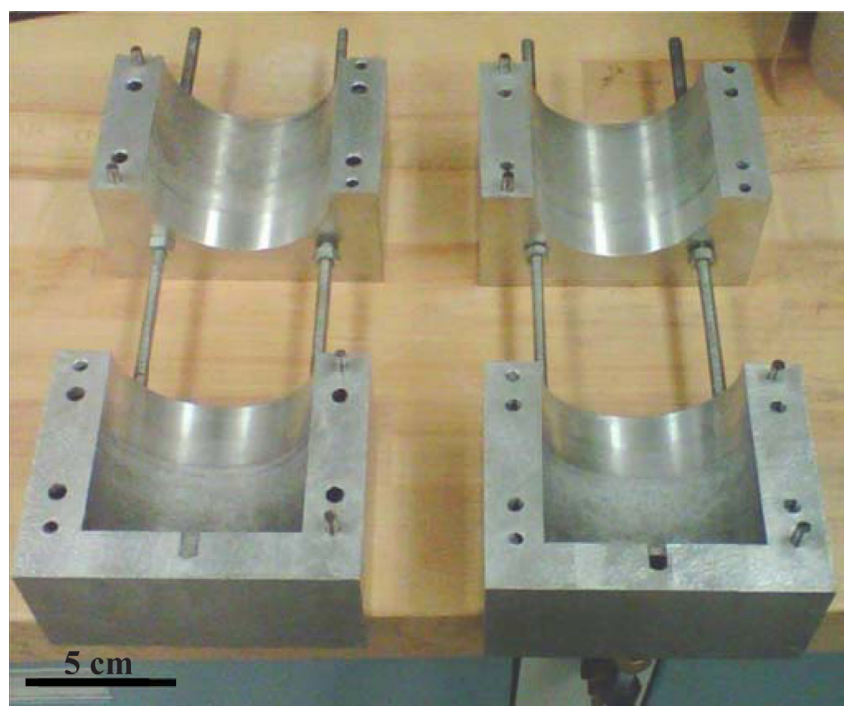

FIG. 5-Step I of assembly - connect the two halves of the top and bottom split molds.

\section{Testing Procedures}

\section{Split Mold Assembly}

The aluminum, three-way split mold is a unique device and assembly must be done carefully to help assure that all joints are tight and leak free. The following gives a detailed outline of the steps taken to assemble and utilize the mold effectively.

Step $I$ - Both halves of the upper and lower portions of the split mold are assembled separately on the threaded rods as seen in Fig. 5. The upper and lower split mold halves with holes for the locking screws must be on the same set of threaded rods. One nut on each threaded rod can be adjusted to mark the location of the upper split mold. The space between the bottom and top split molds can be adjusted to increase or decrease the amount of filter material and sand needed in the top and/or bottom split molds. The only restriction on this spacing is to keep it short enough so that the Orings at the top and bottom of the central split mold will still overlap with the top and bottom split molds to ensure a tight seal. Once the desired length is established, the contact areas of the split mold halves are covered with a thin layer of vacuum grease to account for scratches and irregularities and to assure a good seal.

Step II-The central split mold is cleaned, the joints are lightly greased, the two halves are aligned, and the mold is adequately tightened by two steel hose clamps. Three O-rings are then stretched on both the top and bottom of this mold. The first O-ring on each side is placed in the O-ring groove to provide a seal between the central split mold and each of the top and bottom split molds. A thin layer of grease is applied over these O-rings to further ensure the integrity of the seal. The other two O-rings on each side will be used later to seal the specimen to the top and bottom platens of a triaxial cell. For these two O-rings, the central split mold is used as an O-ring stretcher to avoid any disturbance to the specimen when placing the O-rings later on.

Step $I I I$ - The latex membrane ( $0.3 \mathrm{~mm}$ thickness) is cut precisely to a length such that, when stretched over the interior of the central split mold and rolled over the outer edge of the mold, it reaches just short of the O-rings, as seen in Fig. 6. Because of the $0.6 \mathrm{~mm}$ difference between the inner diameter of the top and bottom split molds and the outer diameter of the central split mold, the rolled over portion of the membrane will not be damaged during the final assembly. Vacuum is applied to the central split mold to help the latex membrane assume the shape of the mold. Care is taken so that the membrane is not twisted or over-stretched within the central split mold since these conditions can cause unnecessary and unknown stresses on the specimen once the vacuum is removed.

Step $I V$ - The central split mold is positioned on the half of the assembly discussed in the first step that contains the threaded holes for the locking screws as seen in Fig. 6. The central split mold is placed such that the O-rings fall approximately $5 \mathrm{~mm}$ within the edges of the top and bottom split molds and the vacuum lines are on a horizontal plane.

Step $V$-The second half (with the unthreaded holes for the locking screws) is placed on top of the first half of the split mold 


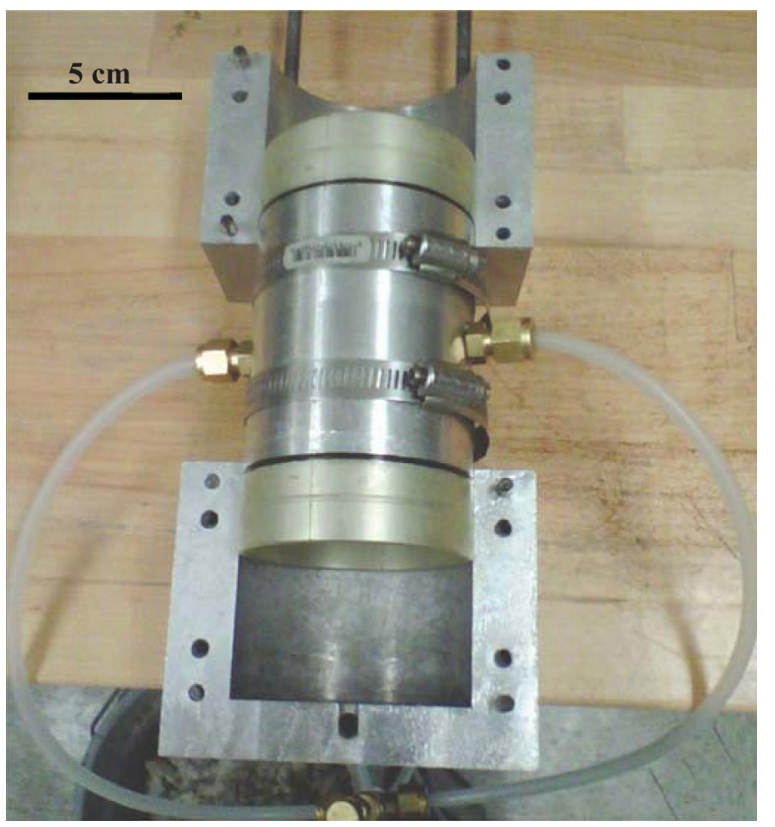

FIG. 6-Steps II-IV of assembly-completely assembled central split mold adjusted in place.

(with the inlet valve facing down) and the locking screws are inserted and tightened as shown in Fig. 7. At this point, the fully assembled mold (except for the top cap) is stood up and ready to contain a new specimen. The top cap will be placed after pluviating the soil into the mold.

\section{Specimen Preparation}

As described previously, this three-way split mold is designed to test cohesionless soils permeated with non-cementing grouts. The resulting material is usually insufficiently strong to stand under its own weight and requires a minimum amount of confinement throughout specimen preparation. The procedure described in the following paragraphs outlines the steps to prepare grouted sand specimens using the three-way split mold for triaxial tests. This

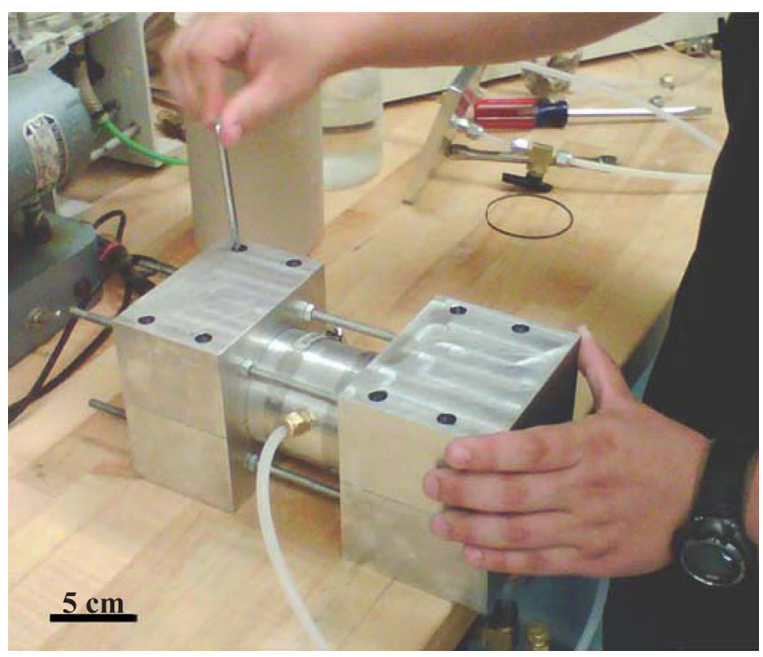

FIG. 7-Step V of assembly-tightening both halves of the top and bottom split molds.

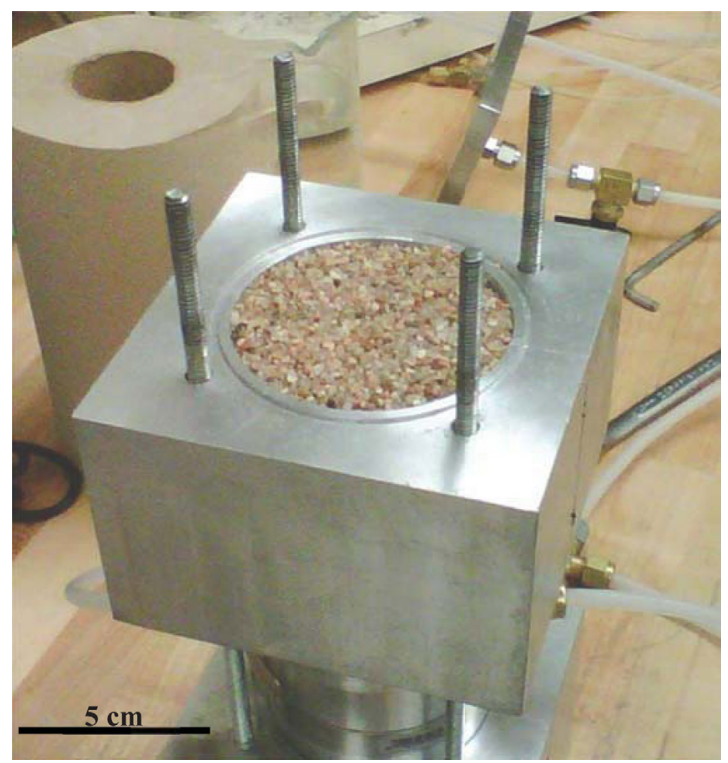

FIG. 8-Three-way split mold with specimen and filter material in (just before placing top cap).

procedure can and should be slightly altered to accommodate the testing of different materials under different conditions.

First, the filter material is placed in the bottom third of the split mold (about $40 \mathrm{~mm}$ thick). The filter material is added to aid in the permeation of the specimen. It allows the bentonite suspension to propagate horizontally and vertically forming a uniform front before reaching the targeted sand. The top of the filter material should be at least $10 \mathrm{~mm}$ below the bottom edge of the central split mold. The presence of this gap will allow the grouted sand to start below the central split mold; thus allowing for trimming out any caking that might occur at the bottom of the grouted sand and create a more uniform specimen within the central split mold.

After the placement of the filter materials, sand is air-pluviated with a funnel. The drop height of the sand was controlled by the operator and, as a result, there was a slight variation in the relative densities of each specimen. This user controlled drop height between the funnel and the top of the sand/filter material in the mold can be adjusted, along with the funnel diameter, depending on the desired final relative density; higher free drop height of sand and a larger diameter funnel results in denser specimens. The sand is pluviated through the central mold and into the top split mold; the sand should extend at least 10-20 mm beyond the top of the central split mold for trimming purposes. Finally, a layer of filter material (approximately $10 \mathrm{~mm}$ thick) is placed at the top of the specimen to prevent sand from piping out through the effluent tube (see Fig. 8). Next, an O-ring is placed in the groove on the upper face of the top split mold and is covered in a thin layer of vacuum grease. The top cap is then secured in place on the threaded rods with four nuts. A photograph of the completely assembled split mold is shown in Fig. 9.

The specimen is then slowly flushed with $\mathrm{CO}_{2}$. Following the $\mathrm{CO}_{2}$ flushing stage, the specimen is saturated with de-aired water at a slow rate not to disturb the sand structure. Approximately two pore volumes of de-aired water are flushed through the specimen. At this stage, the specimen is close to saturation and ready to be 


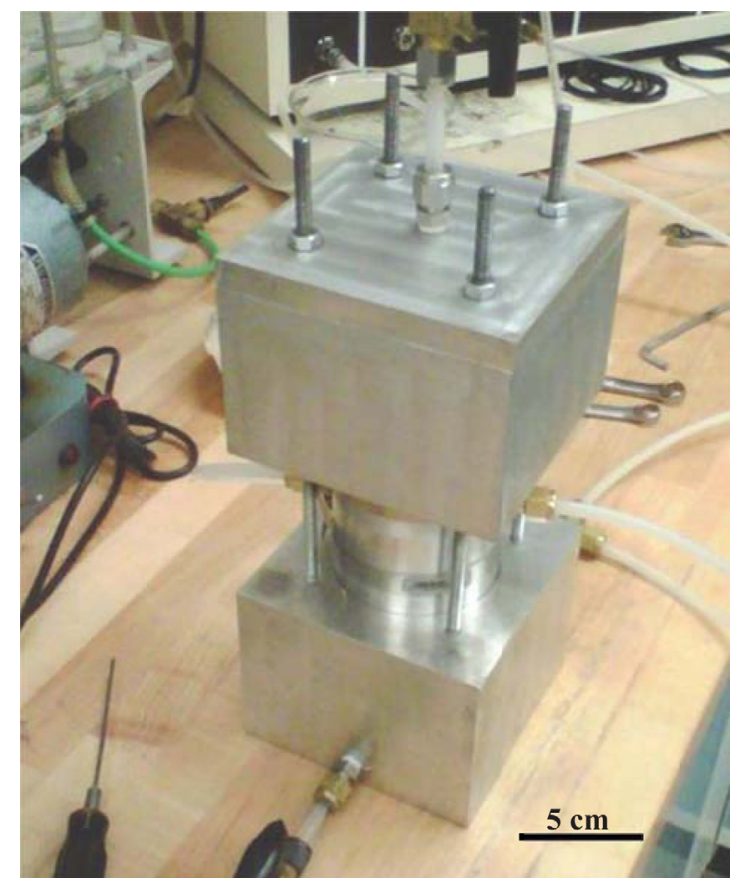

FIG. 9-Completely assembled split mold.

grouted. A schematic of the grouting setup can be seen in Fig. 10. The specimen is grouted using a peristaltic pump with varying flow rates up to $100 \mathrm{~mL} / \mathrm{min}$. The pressure is monitored at the base of the mold during permeation. Prior to permeation, care should be taken to ensure that all lines connected to the specimen are saturated. The specimen is then grouted.

Following successful grouting, the influent and effluent lines to the split mold are shut and the specimen is allowed a period of rest. Grouting was considered to be successful when one full pore volume of grout (or more) was permeated into a specimen utilizing less than $250 \mathrm{kPa}$ of pressure. This rest allows for the grout to build up a minimal strength within the pore spaces, creating a material

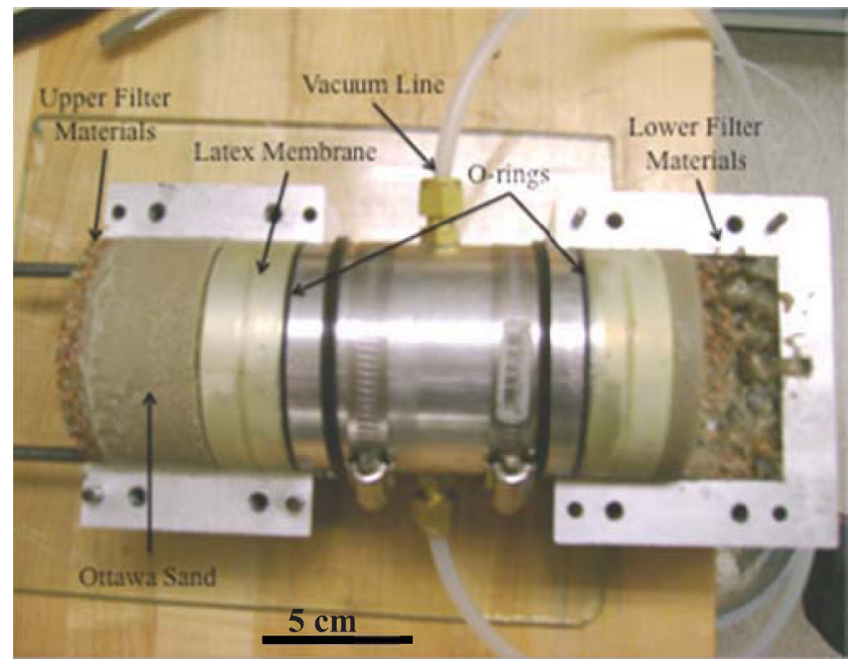

FIG. 11-Partially dissembled grouted specimen with half of the bottom filter material trimmed.

that can be easily trimmed. This time should vary depending on the grout used. After the rest period, the split mold is disassembled. First, the top cap is removed and then the split mold is rested on its side with the locking screws facing upward (similar to Fig. 7). The locking screws are then removed and the upper halves of the top and bottom split molds are taken off. A completely permeated, partially disassembled specimen can be seen in Fig. 11.

Next, the filter materials are removed from the top and bottom split molds along with part of the grouted sand. Approximately $0.5-1 \mathrm{~cm}$ of the grouted sand is left protruding from the central split mold before it is removed from the remaining halves of the top and bottom split molds (Fig. 12(a)). If the length of the soil extending beyond the mold is too long, this could cause negative tensile stresses at the top and cause cracking or breakage of the specimen. A steel wire saw is then used to trim the remaining permeated sand from the central split mold. Special care should be taken to protect the membrane during the trimming stage so that it

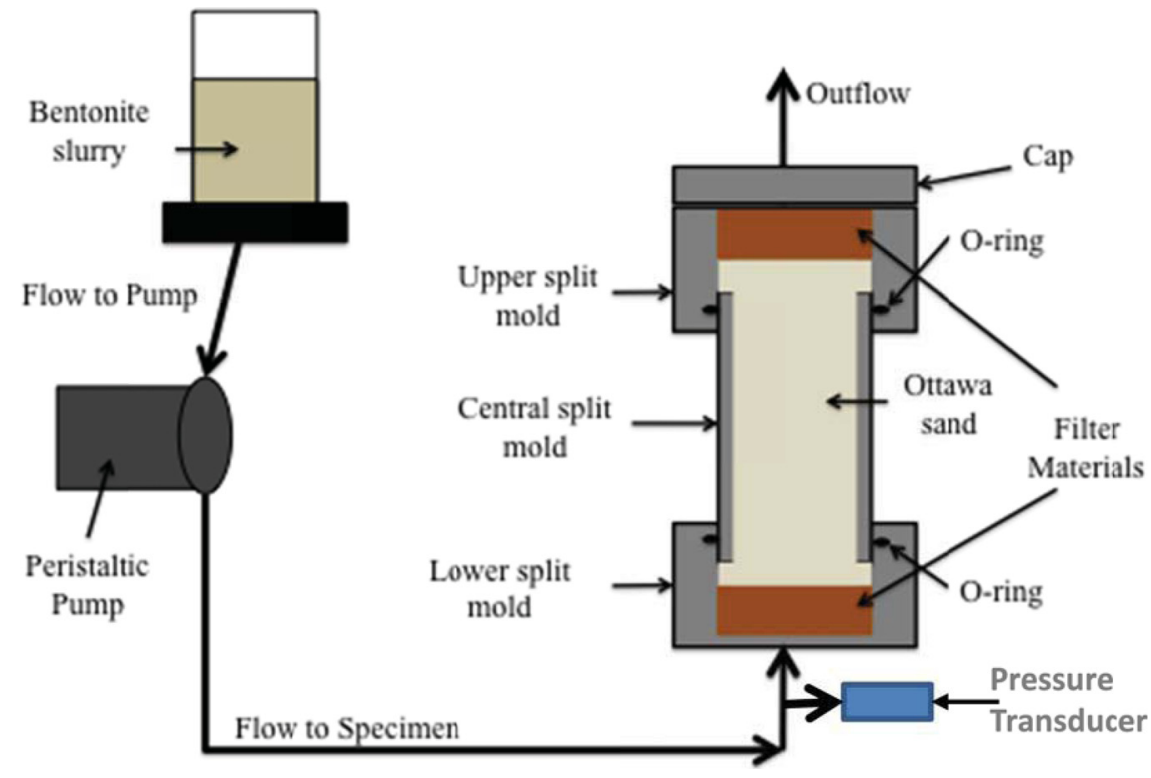

FIG. 10-Schematic of permeation setup using the peristaltic pump. 

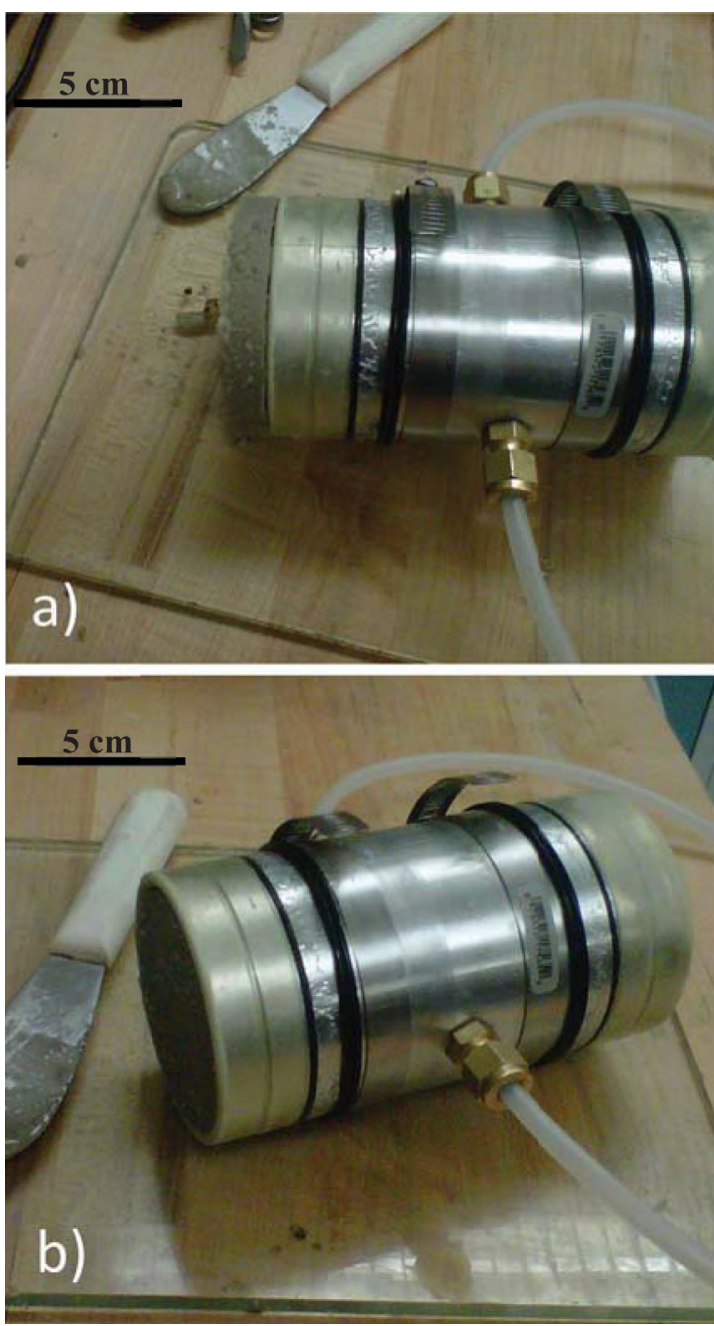

FIG. 12-Central split mold (a) with $10 \mathrm{~mm}$ of permeated sand left, and (b) after trimming.

is not sliced or punctured. After the specimen is adequately trimmed, as seen in Fig. 12(b), the membrane is thoroughly cleaned to remove any sand particles or grout that might compromise the integrity of the membrane's seal against the top and bottom platens of the triaxial cell. The specimen is now ready to be placed in the triaxial cell.

A saturated filter paper and a saturated porous stone are then placed on the triaxial base platen. The specimen is stood up vertically and carefully placed on the base platen, while still inside the central split mold (with vacuum still applied between the mold and membrane) as seen in Fig. 13. The top filter paper and porous stone are then placed on top of the specimen and the top platen is aligned and set in place. A thin layer of vacuum grease is placed on the top and bottom platens before placing the specimen in the triaxial cell to help ensure a tight seal between the membrane and the platens. Next, the membrane is rolled up onto to the top platen and down onto the base platen and the O-rings are then rolled into place. A vacuum is applied to the specimen through the top and bottom pore pressure lines prior to removing the central split mold. This vacuum puts the specimen under minimal confining pressure as the central split mold is disassembled. The triaxial cell is then completely assembled and the testing performed in a simi-

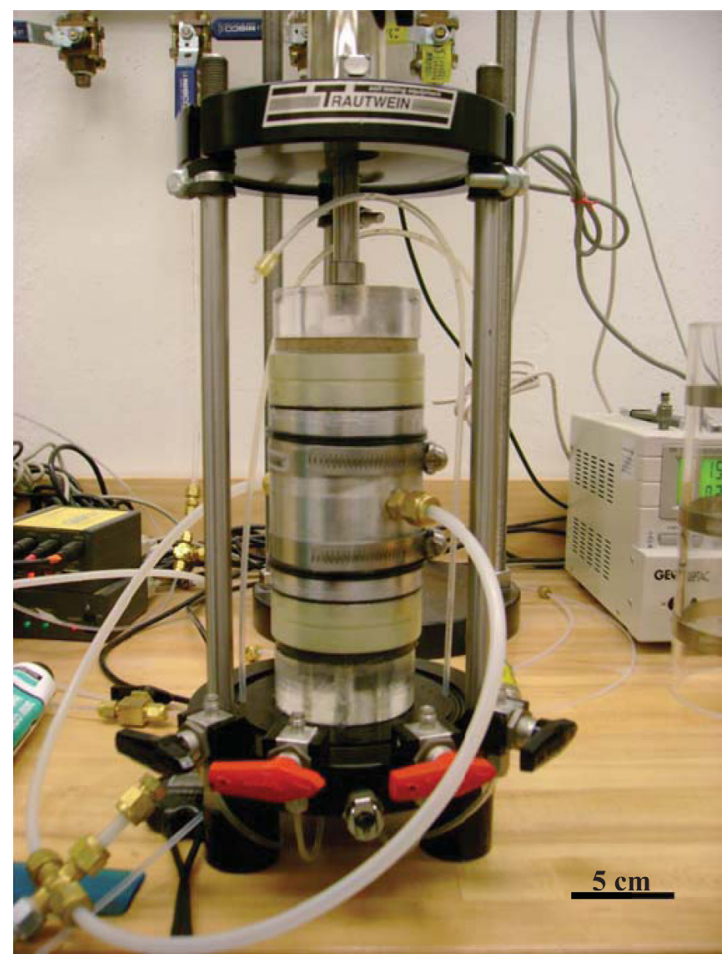

FIG. 13-Specimen mounted on the triaxial cell while still confined by the central split mold.

lar manner to any standard triaxial test. After the completion of the test, the final void ratio was calculated from measuring the total mass, total volume, water content, and bentonite content of the specimen. The initial void ratio at the end of grouting was backcalculated from the recorded volume changes during the different testing stages.

\section{Preliminary Results}

The main purpose of this section is to show that the three-way split mold can be used to test uncemented grouted sands that would not be possible to test with the previous specimen preparation techniques found in the literature. These tests were performed to determine the effect of bentonite grouts on the static liquefaction of a loose fine sand. Only preliminary results are presented here since the main scope of the paper is to introduce the new specimen preparation method.

\section{Materials}

Ottawa sand (ASTM graded sand C778) was utilized for these tests as the sand to be grouted. A summary of Ottawa sand properties can be seen in Table 1. Approximately $20 \mathrm{~mm}$ of fine

TABLE 1-Summary of Ottawa sand properties.

\begin{tabular}{lccc}
\hline Gs & 2.65 & $\mathrm{Cu}$ & 1.61 \\
\hline$e_{\min }$ & 0.50 & $\mathrm{Cc}$ & 1.07 \\
$e_{\max }$ & 0.76 & $D_{10}(\mathrm{~mm})$ & 0.23 \\
USCS & $\mathrm{SP}$ & $D_{60}(\mathrm{~mm})$ & 0.37 \\
\hline
\end{tabular}


TABLE 2-Properties of bentonite (modified from Mitchell and Soga 2005).

\begin{tabular}{lccc}
\hline PL & $35 \%$ & CEC & $80-150 \mathrm{meq} / 100 \mathrm{~g}$ \\
\hline LL & $190 \%-1160 \%$ & Specific area & $700-800 \mathrm{~m}^{2} / \mathrm{g}$ \\
Initial water content & $8.3 \%$ & Swelling capacity & $8 \mathrm{~mL} / \mathrm{g}$ \\
\hline
\end{tabular}

aggregate (Pea stone, diameter $>4.75 \mathrm{~mm}$ ) and $20 \mathrm{~mm}$ of coarse sand $(1.2 \mathrm{~mm}<$ diameter $<1.75 \mathrm{~mm})$ were used as the two layers for the bottom filter materials. These filter materials were selected based on the grain size distribution of the Ottawa sand and to satisfy Terzaghi's retention criteria for filters.

Wyoming sodium-bentonite grade CP-200 was used to prepare the grouts for these tests. A summary of the bentonite clay properties can be found in Table 2. Grouts with $7.5 \%$ and $10 \%$ bentonite by total mass of the grout were prepared using high shear mixing. Since these grouts were too viscous to be permeated through the fine sand selected, the grouts were modified using SPP. Sodium pyrophosphate has a specific gravity of 1.8. The chemical structure of the SPP is $\mathrm{Na}_{4} \mathrm{P}_{2} \mathrm{O}_{7} \cdot 10 \mathrm{H}_{2} \mathrm{O}$ and the molecular weight is 446.06 . The $p \mathrm{H}$ of a $5 \%$ solution was measured to be 9.5 using a JENCO $60 \mathrm{pH}$ meter. The SPP was selected because, while it significantly reduces the initial viscosity of the bentonite suspensions, the viscosity is recovered over time (Clarke 2008). 1\% and 2\% SPP by dry mass of bentonite were added to the $7.5 \%$ and $10 \%$ bentonite grouts, respectively. De-ionized de-aired water was used for the preparation of all bentonite grouts and for all triaxial tests.

\section{Specimen Preparation Specifics}

The specimen preparation method was similar to the one listed in the previous sections. To avoid repetition, the specifics of the specimen preparation are listed in the order of occurrence during the process:

(1) During Ottawa sand pluviation, the funnel was kept approximately $5 \mathrm{~mm}$ from the top of the sand to produce loose sand specimens (relative density of $35 \%-40 \%$ ).

(2) Following the air pluviation of the sand specimens, $\mathrm{CO}_{2}$ was slowly flushed through the specimen; $\mathrm{CO}_{2}$ is used since it dissolves more readily in water at low pressures and room temperature than regular air and will help achieve higher degrees of saturation later on during the backpressure stage. After flushing with $\mathrm{CO}_{2}$, two pore volumes of de-aired and de-ionized water were flushed through the specimen at a flow rate of approximately $6 \mathrm{~mL} / \mathrm{min}$. This allowed the specimens to be as close to saturation as possible (without the use of backpressure) prior to permeation.

(3) The specimens were grouted using a peristaltic pump at a rate of $20 \mathrm{~mL} / \mathrm{min}$. The pressures were monitored at the base of the mold during grouting and the test was termi- nated if the pressures reached $250 \mathrm{kPa}$. The complete grouting took around $25 \mathrm{~min}$.

(4) After grouting, the specimens were allowed $48 \mathrm{~h}$ resting time before starting the disassembling process.

(5) After placement in the triaxial cell, the specimens were subjected to $-25 \mathrm{kPa}$ pore pressure before removing the vacuum between the membrane and the central split mold and dissembling the central split mold. The negative pore pressures were applied from the top and monitored from the base using a pore pressure transducer to insure that the vacuum was applied uniformly across the specimen.

(6) The triaxial cell was then completely assembled and a cell pressure of $25 \mathrm{kPa}$ was applied while removing the negative pore pressure and maintaining a constant effective stress. Specimens were then backpressure saturated to achieve a Bvalue of at least 0.95 before being consolidated to the final effective confining stress of $150 \mathrm{kPa}$. It generally took between 200 and $300 \mathrm{kPa}$ of backpressure to reach the desired saturation values. Finally, the specimens were sheared undrained with pore pressure measurements ( $\overline{\mathrm{CU}}$ tests).

For the clean sand specimen, the sand was air pluviated into the triaxial split mold with a $5 \mathrm{~mm}$ free drop to generate a loose specimen with a relative density between $35 \%$ and $40 \%$. The specimen was kept under $25 \mathrm{kPa}$ confining pressure while being flushed with $\mathrm{CO}_{2}$ and de-aired water. The sand was then backpressure saturated to reach a B-value of 0.95 or higher before being consolidated to $150 \mathrm{kPa}$ and sheared undrained. More details on the clean sand specimen and grouted specimen preparation can be found in Rugg (2010). By using similar pluviation methods for preparing the sand specimens and the grouted specimens, the effects of the grout can be better compared.

\section{Permeation Results}

Table 3 shows some of the pertinent information regarding three permeated specimens. These specimens were permeated in the three-way split mold with either a $10 \%$ bentonite suspension (with $2 \%$ SPP) or a $7.5 \%$ bentonite suspension (with $1 \%$ SPP). As seen in Table 3 , the $10 \%$ bentonite suspensions required maximum permeation pressures near $175 \mathrm{kPa}$, while the $7.5 \%$ bentonite suspensions only required approximately $30 \mathrm{kPa}$ maximum permeation pressure. The skeletal relative densities of these specimens were between $35 \%$ and $40 \%$ and the total permeation time was on the order of 25-30 min. The large change in permeation pressures between the $10 \%$ bentonite suspensions and the $7.5 \%$ bentonite suspensions can be explained by the difference in rheological properties described in the following paragraph and displayed in Fig. 14.

Figure 14 shows the change in yield stress over time for $7.5 \%$ and $10 \%$ bentonite suspensions with and without SPP. The yield

TABLE 3-Representative permeation results for various grouted specimens (modified from Rugg 2010).

\begin{tabular}{|c|c|c|c|c|c|}
\hline Specimen & Suspension & Max pressure, $\mathrm{kPa}$ & Permeation time, min:s & Bentonite content, $\%$ & $D_{R}, \mathrm{sK}, \%$ \\
\hline 20091202 & 10B2SPP & 173 & $30: 24$ & 2.27 & 36.9 \\
\hline 20091209 & 10B2SPP & 172 & $23: 17$ & 2.39 & 35.4 \\
\hline 20100709 & 7.5B1SPP & 31 & $23: 40$ & 1.71 & 40 \\
\hline
\end{tabular}




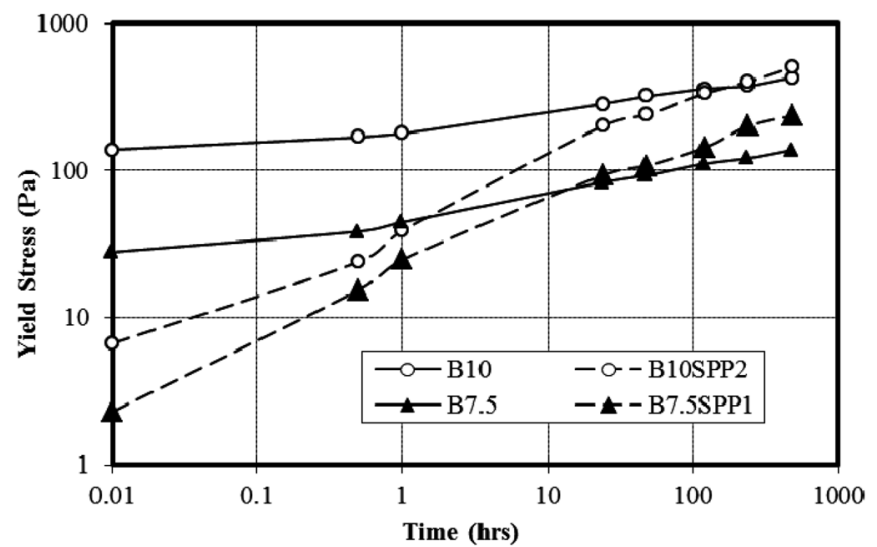

FIG. 14 - Rheological properties for $10 \%$ and $7.5 \%$ bentonite suspensions.

stress of the $7.5 \%$ and $10 \%$ bentonite suspensions decreases significantly with the addition of $1 \%$ and $2 \%$ SPP, respectively. The yield stress of the suspensions with SPP show a much higher thixotropic increase in the yield stress over the first $24 \mathrm{~h}$ compared to that of the untreated bentonite suspensions; eventually, the yield stress of the suspensions with SPP exceeds that of the untreated suspensions. This significant reduction in the initial yield stress increases the mobility of the suspensions and allows for successful permeation.

Table 4 shows the bentonite content at the top, middle, and bottom of each of the specimens described in Table 3. The average bentonite content in the specimens permeated with the $10 \%$ bentonite suspensions is around $2.3 \%$ by dry mass, while the average bentonite content in the specimen permeated with a $7.5 \%$ bentonite suspension is approximately $1.7 \%$. Table 4 shows that a slight filtration effect occurs along the length of the specimen. It can be seen that the bentonite content at the base of each specimen is slightly higher than the bentonite content at the top of each specimen. Figure 15 shows the grout pore pressure versus time during the permeation process. The linear increase in pressure with time indicates that little to no caking occurs during the permeation process. The bentonite content was assumed to be uniform across the horizontal cross section of the specimen and the boundary had no effect on the bentonite flow through the specimen. The sand used is a fine sand with $d_{50}=0.35 \mathrm{~mm}$ and $d \max =0.7 \mathrm{~mm}$. The diameter of the specimen is $71 \mathrm{~mm}$ (100 times the maximum particle diameter); therefore, the boundary effects can be neglected.

\section{Undrained Triaxial Test Results}

The results from four undrained monotonic triaxial tests are presented in this section. The four tests were run on a clean sand specimen, a specimen permeated with $7.5 \%$ bentonite and $1 \%$

TABLE 4-Bentonite content at the top, middle, and bottom of three permeated specimens.

\begin{tabular}{lccc}
\hline \multicolumn{3}{c}{ Bentonite content, \% } \\
\hline Specimen & 20090709 & 20091202 & 20091209 \\
Top & 1.68 & 2.09 & 2.37 \\
Middle & 1.68 & 2.32 & 2.37 \\
Bottom & 1.77 & 2.42 & 2.41 \\
\hline
\end{tabular}

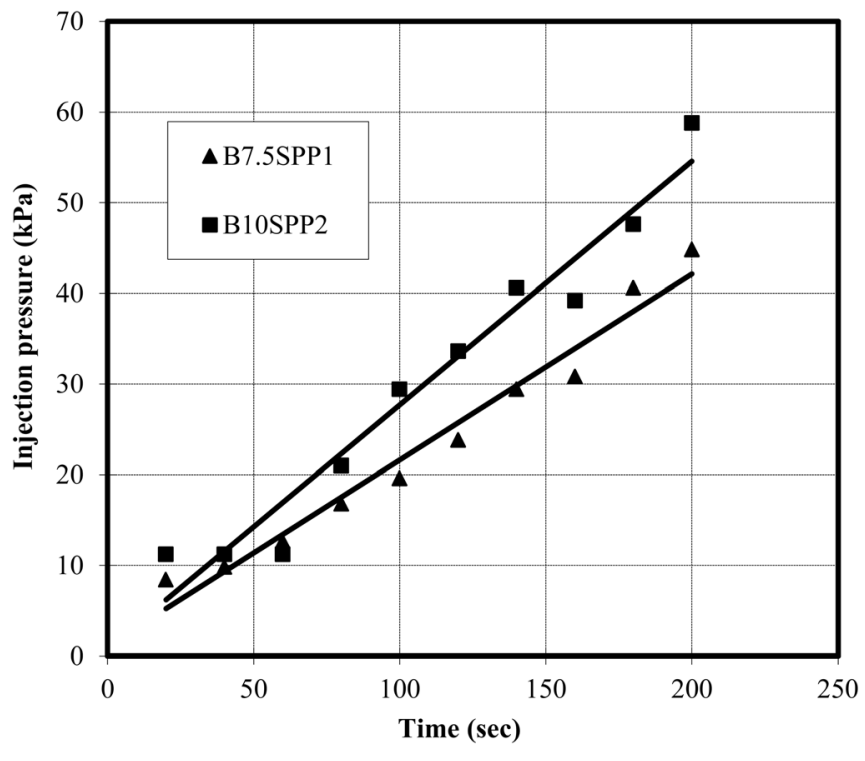

FIG.15-Grouting pressure versus time.

SPP (7.5B1SPP) and two specimens permeated with $10 \%$ bentonite and $2 \%$ SPP (10B2SPP and 10B2SPP-2). Figure 16 shows the deviatoric vertical stress $\left(\sigma_{1}-\sigma_{3}\right)$ versus the axial strain $\left(\varepsilon_{a} \%\right)$ for the three tested specimens. The clean sand specimen shows a typical behavior with the deviatoric stresses increasing up to a local peak (undrained instability state or UIS as defined by Murthy et al. 2007) and then starts dropping, showing a tendency to liquefy and flow. Since the tested specimens all had a skeletal relative density (for the sand specimen, the skeletal and bulk relative density are the same) of $35 \%-40 \%$, the sand specimen did not undergo static liquefaction, but rather started dilating when the axial strains exceeded $2 \%$. This phase transformation from contractive to dilative behavior can be seen in the excess pore pressure generation plot shown in Fig. 17. The positive excess pore pressures start decreasing when the axial strains exceed $2 \%$ and negative pore pressures are generated at higher strains.

The permeated specimens did not show any UIS (Fig. 16), but rather a slow change in the slope of the stress-strain curve. This

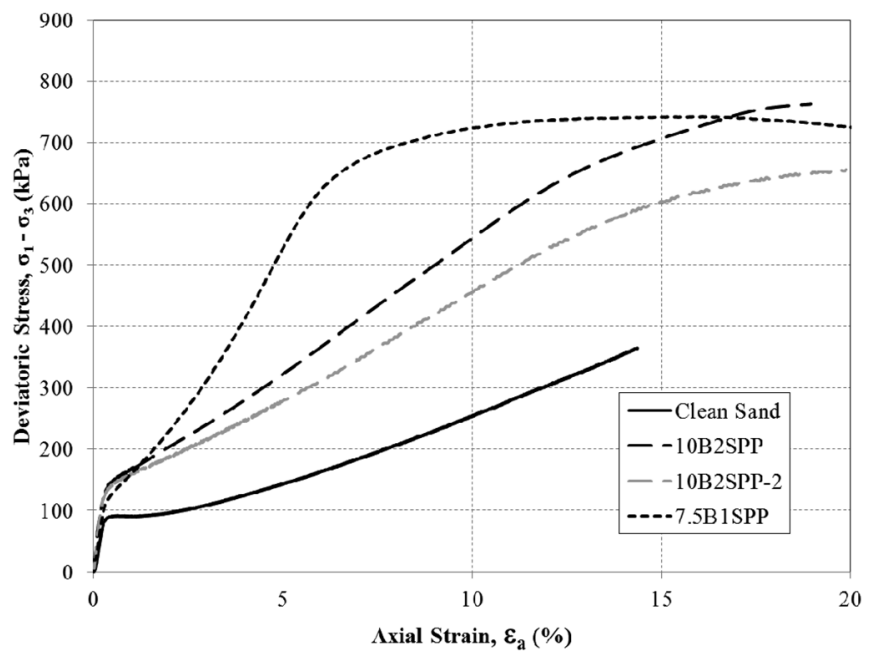

FIG. 16-Deviatoric stress versus axial strain from the $\overline{C U}$ tests. 


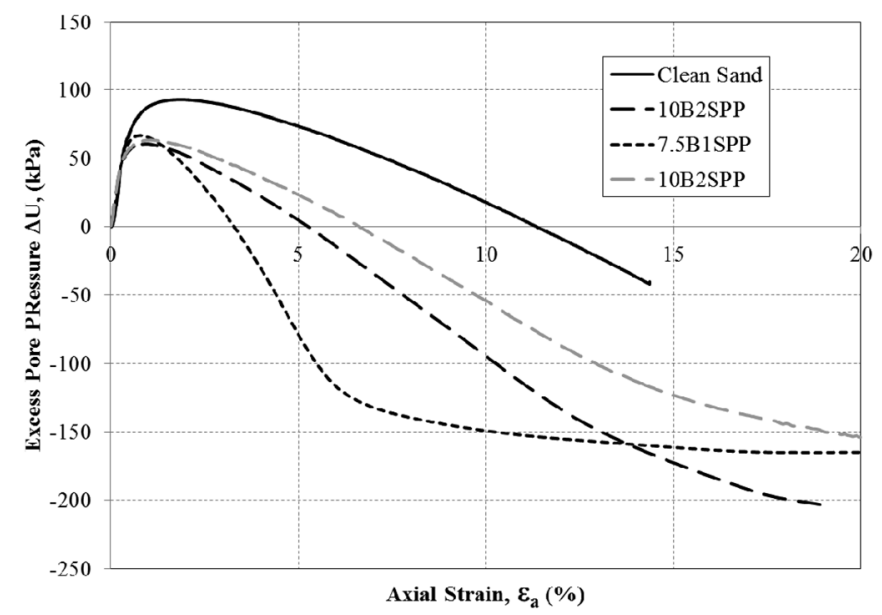

FIG. 17-Excess pore pressure versus axial strain from the $\overline{C U}$ tests.

can be easily explained by the lower positive excess pore pressures generated during shearing of the permeated specimens and the more rapid phase transformation to a dilative behavior. This more rapid phase change results in the generation of negative pore pressures at much lower strains (3\% and 5\% axial strain as compared to $12 \%$ axial strain for the clean sand). This more rapid phase transformation can be clearly seen in Fig. 18 as well; the figure shows the $q-p^{\prime}$ plot for the three specimens. The clean sand plot shows the tendency for static liquefaction with the curve propagating left before the phase transformation and having $p^{\prime}$ and $q$ increasing simultaneously. The permeated specimens showed a much reduced tendency for static liquefaction with higher bentonite concentration in the grouts; the plot for the grouted sand is to the right of the clean sand plot. This change in response under static loading, from the limited results presented in this paper, indicates a higher resistance to static liquefaction due to the reduction in the generation of positive pore pressures.

Table 5 shows the stress ratio $\left(R=\sigma^{\prime}{ }_{1} / \sigma^{\prime}{ }_{3}\right)$ values and equivalent secant friction angle at the UIS and CS for the three specimens. For the grouted sands, since there is no true UIS, the location of the initial change in slope on the stress-strain plots was used to calculate $R_{\text {UIS }}$. The critical state values are calculated at

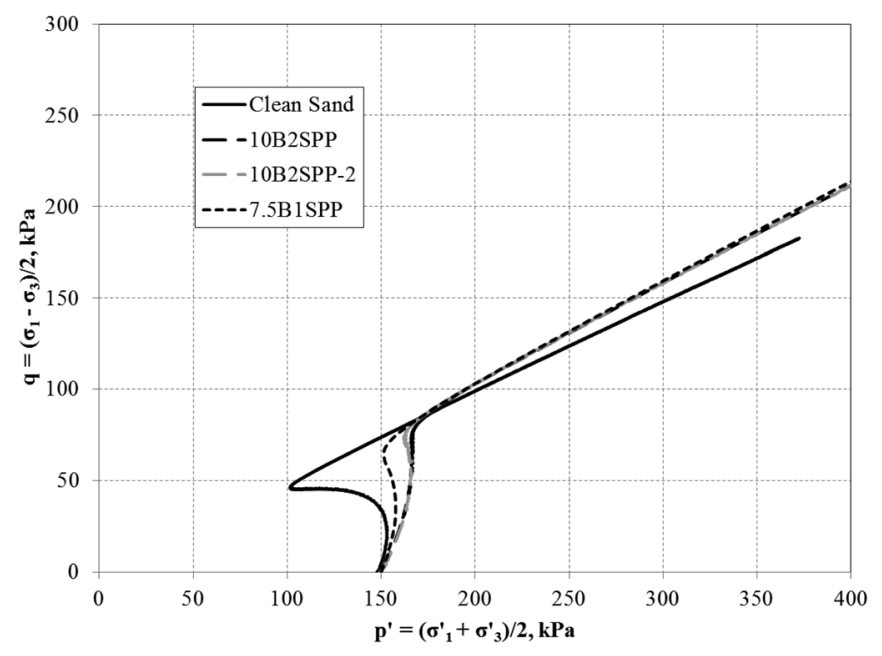

FIG. 18-Stress path of the tested soils.
TABLE 5-Stress ratio and internal friction angle.

\begin{tabular}{lcccc}
\hline & $R_{\mathrm{UIS}}$ & $\varphi^{\prime}{ }_{\text {UIS }}$ & $R_{\mathrm{CS}}$ & $\varphi^{\prime} \mathrm{CS}$ \\
\hline Clean sand & 2.11 & $21^{\circ}$ & 2.88 & $29^{\circ}$ \\
$7.5 \mathrm{~B} 1 \mathrm{SPP}$ & 2.20 & $22^{\circ}$ & 3.12 & $31^{\circ}$ \\
$10 \mathrm{~B} 2 \mathrm{SPP}$ & 2.19 & $22^{\circ}$ & 3.11 & $31^{\circ}$ \\
\hline
\end{tabular}

higher strains and can be backcalculated from the final slopes in Fig. 18. The clean sand and grouted specimens show similar shear strength properties despite the introduction of the grout into the pores. These results, in particular the UIS results, which occur at small strains (less than $0.5 \%$ axial strain), indicate that there is little change to the sand structure during grouting as well as during specimen preparation and installation into the triaxial cell. These combined results clearly show the applicability of using the threeway split mold to prepare uncemented, cohesionless, grouted sand triaxial specimens without damaging the structure of the sand.

\section{Summary and Conclusions}

A new three-way split mold was developed for preparing triaxial specimens of uncemented grouted sands. The new mold consists of three inter-connected split molds that allow for preparing a uniformly grouted specimen by having a filter material at the base and top that can eventually be trimmed out when preparing the final specimen to be tested. This new specimen preparation procedure provides a minimal confinement throughout the specimen preparation stages; this is critical to preserve the soil structure when the grouted soil is not strong enough to stand alone. Finally, preliminary tests on sand specimens grouted with bentonite suspensions were presented to show a possible application for the new mold. The results showed a reduction in the tendency of the sand to liquefy under static loading in the presence of the bentonite grout in the pore space. These results also showed that the grouting did not have a significant effect on the shear strength of the sand, indicating that the specimen preparation method was successful in retaining the original sand structure. This hypothesis is further justified by the similar secant friction angles at low strains for both clean and grouted sands. While the uniformity of permeation grouting in the field would remain a big concern, the proposed mold and testing procedures open the door for laboratory testing on soft grouted specimens that was not feasible before.

\section{Acknowledgments}

The writers would like to acknowledge the Civil, Environmental and Architectural Engineering Department at the University of Texas at Austin for the financial support provided to Mr. Rugg during the period of this project.

\section{References}

ASTM C39/C39M, "Standard Test Method for Compressive Strength of Cylindrical Concrete Specimens," Annual Book of ASTM Standards, ASTM International, West Conshohocken, PA. Bell, F.G., 1993, Engineering Treatment of Soils, E\&FN Spon, London. 
Benhamou, O., 1994, "Comportement rhéologique des coulis de liants hydrauliques ultrafins destinés àl'injection [Rheological behavior of ultrafine cement slurry intended for injection]," Ph.D. thesis, Ecole de Géologie de l'Ingénieur, Ecole Nationale Supérieure des Mines de Paris (in French).

Broms, B., 1991, "Deep Compaction of Granular Soil," Foundation Engineering Handbook, 2nd ed., H.-Y. Fang, Ed., Van Norstrand Reinhold, New York, pp. 814-832.

Clarke, J., 2008, "Investigation of Time-Dependent Rheological Behavior of Sodium Pyrophosphate - Bentonite Suspension," Masters thesis, Purdue University, West Lafayette, IN.

Dano, C., Hicher, P., and Tailliez, S., 2004, "Engineering Properties of Grouted Sands," J. Geotech. Geoenviron. Eng., Vol. 130, No. 3, pp. 328-338.

Dupla, J., Canou, J., and Gouvenot, D., 2004, “An Advanced Experimental Set-Up for Studying a Monodirectional Grout Injection Process," Ground Improvement, Vol. 8, pp. 91100.

El Mohtar, C. S., 2008, "Pore Fluid Engineering: An Autoadaptive Design for Liquefaction Migration," Ph.D. thesis, Purdue University, West Lafayette, IN.

El Mohtar, C. S., Clarke, J., Bobet, A., Santagata, M., Drnevich, V., and Johnston C., 2008, "Cyclic Response of a Sand with Thixotropic Pore Fluid," Geotechnical Special Publication, $n$ 181, 2008, Proceedings of the Geotechnical Earthquake Engineering and Soil Dynamics IV Congress 2008-Geotechnical Earthquake Engineering and Soil Dynamics, Geotechnical Special Publications (GSP) 181, Vol. IV.

Gallagher, P., 2000, "Passive Site Remediation for Mitigation of Liquefaction Risk," Ph.D. dissertation, Virginia Politechnic Institute and State University, Blacksburg, VA.

Gallagher, P., and Lin, Y., 2009, "Colloidal Silica Transport through Liquefiable Porous Media," J. Geotech. Geoenviron. Eng., Vol. 135, No. 11, pp. 1702-1712.

Gallagher, P., and Mitchell, J., 2002, "Influence of Colloidal Silica Grout on Liquefaction Potential and Cyclic Undrained Behavior of Loose Sand," Soil Dyn. Earthquake Eng., Vol. 22, No. 9-12, pp. 1017-1026.

Gallagher, P., Pamuk, A., and Abdoun, T., 2007, "Stabilization of Liquefiable Soils Using Colloidal Silica Grout," J. Mater. Civ. Eng., Vol. 19, pp. 33-40.
Haldavnekar, V., Bobet, A., Santagata, M., and Drnevich, V.P, 2003, "Soil Treatment with Thixotropic Fluid: An Autoadaptive Design for Liquefaction Prevention," Proceedings of the 11th International Conference on Soil Dynamics and Earthquake Engineering and 3rd International Conference on Earthquake Geotechnical Engineering, Vol. II, Stallion Press, pp. 553-560.

Hausmann, M. R., 1990, Engineering Principles of Ground Modification, McGraw-Hill, New York.

Kramer, S. L., 1996, Geotechnical Earthquake Engineering, Prentice Hall, Upper Saddle River, NJ.

Liao, H., Huang, C., and Chao, B., 2004, "Liquefaction Resistance of a Colloidal Silica Grouted Sand," Grouting and Ground Treatment, ASCE, Reston, VA.

Maher, M., Ro, K., and Welsh, J., 1994, "Cyclic Undrained Behavior and Liquefaction Potential of Sand Treated with Chemical Grouts and Microfine Cement (MC-500)," Geotech. Test. J., Vol. 17, No. 2, pp. 159-170.

Mitchell, J., and Soga, K., 2005, Fundamentals of Soil Behavior, 3rd ed., Wiley, New York.

Mosely, M. P., 1993, Ground Improvement, Blackie, London.

Murthy, T., Loukidis, D., Carraro, J., Prezzi, M., and Salgado, R., 2007, "Undrained Monotonic Response of Clean and Silty Sands," Geotechnique, Vol. 57, No. 3, pp. 273-288.

Rugg, D., 2010, "Undrained, Monotonic Shear Strength of Loose Saturated Sand Treated with a Thixotropic Bentonite Suspension for Soil Improvement," Master's thesis, The University of Texas at Austin, Austin, TX.

Schwarz, L. G., and Krizek, R. J., 1994, "Effect of Preparation Technique on Permeability and Strength of Cement-Grouted Sand," Geotech. Test. J., Vol. 17, No. 4, pp. 434-443.

Seed, H. B., and Idriss, I. M., 1982, Ground Motions and Soil Liquefaction During Earthquakes, Earthquake Engineering Research Institute, Berkeley, CA.

Van Impe, W. F., 1989, Soil Improvement Techniques and Their Evolution, Balkema, Rotterdam, The Netherlands.

Welsh, J.P., Ed., 1987, "Soil Improvement: A Ten Year Update," Geotech. Spec. Publ. No. 12.

Zebovitz, S., Krizek, R. J., and Atmatzidis, D. X., 1989, "Injection of Fine Sands with Very Fine Cement Grout," J. Geotech. Geoenviron. Eng., Vol. 115, No. 12, pp. 1717-1733. 